\title{
Uterine Corpus Adenomyoma
}

National Cancer Institute

\section{Source}

National Cancer Institute. Uterine Corpus Adenomyoma. NCI Thesaurus. Code C6338.

A usually polypoid, benign neoplasm that arises from the uterine corpus. It is characterized by the presence of benign epithelial glands embedded in benign fibromyomatous tissue. 